\title{
The effect of a decaffeinated green tea extract formula on fat oxidation, body composition and exercise performance
}

\author{
Justin D Roberts ${ }^{1,2^{*}}$, Michael G Roberts ${ }^{2 \dagger}$, Michael D Tarpey ${ }^{2 \dagger}$, Jack C Weekes ${ }^{2 \dagger}$ and Clare H Thomas ${ }^{2+}$
}

\begin{abstract}
Background: The cardio-metabolic and antioxidant health benefits of caffeinated green tea (GT) relate to its catechin polyphenol content. Less is known about decaffeinated extracts, particularly in combination with exercise. The aim of this study was therefore to determine whether a decaffeinated green tea extract (dGTE) positively influenced fat oxidation, body composition and exercise performance in recreationally active participants.

Methods: Fourteen, recreationally active males participated in a double-blind, placebo-controlled, parallel design intervention (mean $\pm \mathrm{SE}$; age $=21.4 \pm 0.3 \mathrm{yrs}$; weight $=76.37 \pm 1.73 \mathrm{~kg}$; body fat $=16.84 \pm 0.97 \%$, peak oxygen consumption $\left.\left[\dot{\mathrm{V}}_{2 \text { peak }}\right]=3.00 \pm 0.10 \mathrm{~L} \cdot \mathrm{min}^{-1}\right)$. Participants were randomly assigned capsulated dGTE $\left(571 \mathrm{mg} \cdot \mathrm{d}^{-1}\right.$; $\mathrm{n}=7$ ) or placebo ( $\mathrm{PL} ; \mathrm{n}=7$ ) for 4 weeks. Following body composition and resting cardiovascular measures, participants cycled for 1 hour at 50\% $\dot{\mathrm{V}} \mathrm{O}_{2 \text { peak, }}$, followed by a 40 minute performance trial at week 0, 2 and 4 . Fat and carbohydrate oxidation was assessed via indirect calorimetry. Pre-post exercise blood samples were collected for determination of total fatty acids (TFA). Distance covered $(\mathrm{km})$ and average power output (W) were assessed as exercise performance criteria.
\end{abstract}

Results: Total fat oxidation rates increased by $24.9 \%$ from $0.241 \pm 0.025$ to $0.301 \pm 0.009 \mathrm{~g} \cdot \mathrm{min}^{-1}$ with dGTE $(P=0.05$; $\left.\eta \mathrm{p}^{2}=0.45\right)$ by week 4 , whereas substrate utilisation was unaltered with PL. Body fat significantly decreased with dGTE by $1.63 \pm 0.16 \%$ in contrast to PL over the intervention period $\left(P<0.001 ; \eta p^{2}=0.84\right)$. No significant changes for FFA or blood pressure between groups were observed. dGTE resulted in a 10.9\% improvement in performance distance covered from $20.23 \pm 0.54 \mathrm{~km}$ to $22.43 \pm 0.40 \mathrm{~km}$ by week $4\left(P<0.001 ; \eta p^{2}=0.85\right)$.

Conclusions: A 4 week dGTE intervention favourably enhanced substrate utilisation and subsequent performance indices, but did not alter TFA concentrations in comparison to PL. The results support the use of catechin polyphenols from dGTE in combination with exercise training in recreationally active volunteers.

Keywords: Green tea, Body composition, Fat oxidation, Exercise performance

\section{Introduction}

The health benefits of polyphenols found in green tea (GT), the unfermented leaves of the tea plant, Camellia sinensis, have been extensively investigated in the last fifteen years [1-7]. Studies have demonstrated antioxidant $[8,9]$ and chemoprotective properties [4], as well as improvements in cardio-metabolic health from various

\footnotetext{
* Correspondence: justin.roberts@anglia.ac.uk

${ }^{\dagger}$ Equal contributors

'Department of Life Sciences, Anglia Ruskin University, East Road, Cambridge, UK

${ }^{2}$ School of Life \& Medical Sciences, University of Hertfordshire, College Lane,

Hatfield, Hertfordshire, UK
}

() Biomed Central

(c) 2015 Roberts et al.; licensee Biomed Central. This is an Open Access article distributed under the terms of the Creative Commons Attribution License (http://creativecommons.org/licenses/by/4.0), which permits unrestricted use, distribution, and reproduction in any medium, provided the original work is properly credited. The Creative Commons Public Domain Dedication waiver (http://creativecommons.org/publicdomain/zero/1.0/) applies to the data made available in this article unless otherwise stated.

GT strategies (including reduced circulating cholesterol and triglyerides [10], increased thermogenesis and whole body fat oxidation $[1,3,11]$, reduced blood pressure $[7,12,13]$ and improved body mass index ratios [5,14-17]). These health benefits, in part, relate to the bioactive catechin polyphenol content of GT, of which (-)-epigallocatechin-3-gallate (EGCG) can account for between 50-80\% of the total catechin content [18].

GT catechins have been proposed to influence metabolic and thermogenic activities in the short term, via inhibition of catechol-o-methyl transferase (COMT) leading to enhanced catecholamine, cAMP and lipolytic activity 
$[17,19,20]$, although this has been disputed [20]. GT catechins, particularly EGCG, may also activate endothelial nitric oxide synthase, leading to mild reductions in blood pressure [13,21].

In the longer term, GT catechins may influence specific signalling molecules, including PGC1 $\alpha$, leading to gene expression of fat metabolism enzymes [20]. Whilst such mechanisms are currently under debate, strategies to enhance fat oxidation, body composition and cardiovascular efficiency in conjunction with physical activity are of pertinence to the general population. Additionally the indirect sparing of glycogen stores may support improved exercise tolerance and/or performance.

Research investigating GT extracts (GTE) and exercise have produced conflicting results. Modest EGCG dosage in the short term (270 mg.d ${ }^{-1}$ EGCG for 6 days [22], and $68 \mathrm{mg} \cdot \mathrm{d}^{-1}$ EGCG for 3 weeks $\left.[23,24]\right)$ did not alter metabolic or performance variables in healthy or endurance trained volunteers. However, the inclusion of $100.5 \mathrm{mg} \cdot \mathrm{d}^{-1}$ EGCG over a 10 week training period enhanced whole-body metabolic efficiency elsewhere [11]. One confounding factor though is the use of caffeinated GTE in these studies. When decaffeinated GTE (dGTE) has been employed, 366 mg EGCG was found to acutely increase fat oxidation by $17 \%$ [3]. Conversely, higher dosage dGTE ( $624 \pm 3 \mathrm{mg} \cdot \mathrm{d}^{-1}$ EGCG for 28 days) did not significantly affect fat oxidation in healthy, male volunteers [25].

We were therefore invited to undertake an independent assessment of the cardio-metabolic and performance effects of a dGTE formula $\left(571 \mathrm{mg}^{-1}\right.$ GTE providing $400 \mathrm{mg} \cdot \mathrm{d}^{-1}$ EGCG) over a 4 week period in comparison to placebo in healthy, male volunteers. It was hypothesised that moderate dose dGTE would significantly improve fat oxidation and performance, supporting longer term mechanisms linking GTE catechins to enhanced metabolic enzyme gene expression.

\section{Materials and methods Participants}

Fourteen healthy, male participants volunteered following power calculation assessment (G*Power3, Dusseldorf [26]; using $\alpha=0.05 ; 1-\beta=0.95$; based on observed data [3,22-24] and 2 groups). Participants were required to be recreationally active non-smokers, and have no known sensitivities to tea products or be regular green tea consumers. Prior to study inclusion, all participants provided written informed consent and satisfactorily completed a general health screen. The study was approved by the University of Hertfordshire Life and Medical Sciences Ethics Committee. Participant characteristics are displayed in Table 1.

\section{Procedures}

\section{Preliminary testing}

All testing took place in the Human Physiology Laboratory, University of Hertfordshire. Participants were instructed to refrain from consuming caffeinated products for 48 hours prior to initial testing, and not be consuming other supplementation.

Peak oxygen consumption $\left(\dot{\mathrm{VO}}_{2 \text { peak }}\right)$ was assessed at least one week prior to experimental trials using a standard incremental step protocol increasing by $30 \mathrm{~W}$ each 3 minutes until volitional exhaustion as previously reported [27]. Tests were performed on a Monark Ergomedic 874E stationary bike (Monark Exercise AB, Varberg, Sweden) using a Metalyser 3B automated gas-analyser (Cortex Biophysik, Leipzig, Germany). On a separate occasion, subjects undertook a familiarisation trial to confirm exercise intensity at $50 \% \dot{\mathrm{V}} \mathrm{O}_{2 \text { peak }}$. This intensity was selected based on pilot work in which average fat oxidation rates during sustained submaximal exercise were statistically greater at $50 \% \dot{\mathrm{V}_{2 p e a k}}$ compared to both 40 and $60 \% \dot{\mathrm{V}}_{2 \text { peak }}$.

\section{Treatments}

Participants were randomly assigned to an experimental or placebo group, and provided with either capsulated dGTE (571 mg. $\mathrm{d}^{-1} \mathrm{dGTE}$, delivering $70 \%$ or $400 \mathrm{mg} \cdot \mathrm{d}^{-1}$ EGCG (equivalent to 6-7 cups of green tea per day), Changsha Active Ingredients Group Inc., Changsha, China"), or placebo (700 mg. $\mathrm{d}^{-1}$ corn flour). All participants received capsules on a weekly basis to monitor compliance, with instructions to consume one capsule daily before breakfast with $250 \mathrm{ml}$ water. "Analysis of the main active ingredient (EGCG) was undertaken prior to and independently of the main study by Changsha Active Ingredients Group Inc., using high performance liquid chromatography. The certificate of analysis provided by the supplying company demonstrated that the product contained $91.21 \%$ total catechins, from which $70.74 \%$ was EGCG. The product did not appear to be assessed for other catechins, so it is likely that the remaining percentage comprised other catechins (GCG, EGC, GC, EC, ECG, etc.).

\section{Experimental design and intervention}

A randomised, double blind, placebo controlled parallel design was employed over a 4 week intervention. Participants completed three laboratory trials at week 0,2 and 4 under controlled conditions following an overnight fast. Upon arrival, nude body mass (Seca 780, Hamburg, Germany), height (Seca 200 stadiometer, Hamburg, Germany) and body composition [28] (Tanita Body Segmental Analyser 418-BC, Tokyo, Japan) were assessed.

Participants were then fitted with a Polar FS2c telemetric monitor (Polar Electro Ltd., Kempele, Finland) and 
Table 1 Baseline characteristics and resting measurements across the intervention

\begin{tabular}{|c|c|c|c|c|c|c|}
\hline Variable & $P L(n=7)$ & & & dGTE $(n=7)$ & & \\
\hline Age (years) & $21.4 \pm 0.6$ & & & $21.4 \pm 0.3$ & & \\
\hline Height (m) & $1.77 \pm 0.03$ & & & $1.78 \pm 0.01$ & & \\
\hline \multirow[t]{2}{*}{$\dot{\mathrm{V}} \mathrm{O}_{2 \text { peak }}\left(\mathrm{L} \cdot \mathrm{min}^{-1}\right)$} & $3.13 \pm 0.18$ & & & $2.87 \pm 0.08$ & & \\
\hline & Baseline & Week 2 & Week 4 & Baseline & Week 2 & Week 4 \\
\hline Weight (kg) & $75.46 \pm 2.91$ & $75.11 \pm 2.94^{*}$ & $74.81 \pm 2.88^{*}$ & $77.29 \pm 2.05$ & $76.96 \pm 2.03^{*}$ & $76.69 \pm 1.95 *^{* B}$ \\
\hline Bodyfat (\%) & $16.63 \pm 1.58$ & $16.34 \pm 1.69$ & $15.97 \pm 1.69^{* \#}$ & $17.06 \pm 1.24$ & $16.23 \pm 1.39^{*}$ & $15.43 \pm 1.33^{* \# A, B}$ \\
\hline HR (bpm) & $61.00 \pm 2.70$ & $62.14 \pm 1.81$ & $61.00 \pm 1.83$ & $62.00 \pm 1.25$ & $62.43 \pm 2.01$ & $62.57 \pm 1.92$ \\
\hline $\mathrm{SBP}(\mathrm{mm} \mathrm{Hg})$ & $129.29 \pm 1.73$ & $125.71 \pm 3.64$ & $127.00 \pm 2.44$ & $130.00 \pm 1.18$ & $126.57 \pm 2.14$ & $126.86 \pm 3.64$ \\
\hline $\mathrm{DBP}(\mathrm{mm} \mathrm{Hg})$ & $67.57 \pm 4.35$ & $66.14 \pm 1.72$ & $69.71 \pm 2.37$ & $69.57 \pm 2.40$ & $65.71 \pm 2.55$ & $67.71 \pm 2.11$ \\
\hline
\end{tabular}

Table 1 shows the key participant characteristics for each group, including absolute changes for weight, body fat, heart rate and blood pressure over the intervention. Data are presented as mean \pm SE. PL, Placebo; dGTE, decaffeinated green tea extract; $\dot{V}_{2}$ peak, peak oxygen uptake; $\mathrm{HR}$, heart rate; SBP, systolic blood pressure; DBP, diastolic blood pressure. ${ }^{A}$ denotes significant overall group $\mathrm{x}$ time interaction effect $(P=0.002) .{ }^{B}$ denotes significant overall time interaction effect only $(P<0.001)$. ${ }^{*}$ denotes significant difference $(P \leq 0.05)$ to baseline only within group. "denotes significant difference to week 2 within group only $(P<0.046)$.

seated for 5 minutes prior to resting heart rate and blood pressure readings (Omron MX3 plus, Kyoto, Japan). A venous wholeblood sample was then collected into duplicate $4 \mathrm{ml} \mathrm{K}{ }_{3}$ EDTA Vacutainers (Greiner Bio-One $\mathrm{GmbH}$, Kremsmunster, Austria) by a qualified phlebotomist. Samples were centrifuged for 10 minutes at $2000 \mathrm{rpm}$, with aliquotted plasma immediately frozen at $-80^{\circ} \mathrm{C}$ for later assessment of TFA.

\section{Exercise trials}

Exercise trials comprised a submaximal assessment and performance stage. During the submaximal assessment, participants exercised for one hour at $50 \% \dot{\mathrm{V}} \mathrm{O}_{2 \text { peak }}$ on a Monark Ergomedic 874E cycle ergometer. Gas exchange data was recorded continuously throughout exercise using a Metalyser 3B gas analyser, with average data taken over the final 45 minutes of submaximal exercise. Rating of perceived exertion (RPE) [29] and heart rate were recorded every 20 minutes.

Rates of total carbohydrate oxidation $\left(\mathrm{CHO}_{\mathrm{TOT}}\right)$, total fat oxidation $\left(\mathrm{FAT}_{\mathrm{TOT}}\right)\left(\mathrm{g} \cdot \mathrm{min}^{-1}\right)$ and energy expenditure (EE) $\left(\mathrm{kJ} \cdot \mathrm{min}^{-1}\right)$ were calculated from $\dot{\mathrm{VO}_{2}}$ and $\dot{\mathrm{VCO}_{2}}$ $\left(\mathrm{L} \cdot \mathrm{min}^{-1}\right)$ using stoichiometric equations [30], with protein oxidation assumed negligible, as follows:

$$
\begin{aligned}
& \left.\mathrm{CHO}_{\mathrm{TOT}}=4.210 \cdot(\dot{\mathrm{VCO}})_{2}\right)-2.962 \cdot\left(\dot{\mathrm{VO}}_{2}\right) \\
& \mathrm{FAT}_{\mathrm{TOT}}=1.695 \cdot\left(\dot{\mathrm{VO}}_{2}\right)-1.701 \cdot\left(\dot{\mathrm{VCO}}_{2}\right) \\
& \mathrm{EE}=\left[\left(0.550 \cdot \dot{\mathrm{V}} \mathrm{CO}_{2}\right)-\left(4.471 \cdot \dot{\mathrm{V}} \mathrm{O}_{2}\right)\right] \bullet 4.2
\end{aligned}
$$

Upon completion, seated blood pressure and post exercise venous sampling was repeated as previously described. Following this, participants were instructed to undertake a 40 minute self-paced performance trial using a Computrainer erogometer system (RaceMate
Inc., Seattle, USA). Distance covered $(\mathrm{km})$ and power output (W) were recorded each 10 minutes, with only time elapsed visible to the subjects. Verbal encouragement was provided each 10 minutes. At the end of the exercise trial, subjects recovered for 5 minutes at $50 \mathrm{~W}$.

\section{Dietary intake and exercise activity}

All participants recorded a 3 day dietary recall preceding each exercise trial to assess for habitual dietary compliance. Dietary analyses were undertaken using Dietplan 6.50 (Forestfield Software Ltd, West Sussex, United Kingdom), with no differences reported between groups for macronutrients and/or energy intake. Additionally, participants were requested to consume similar meals the day before the exercise trials at regular time intervals to provide increased control of oxidation variables. This was based on pilot work assessment of fat oxidation stability at $50 \% \dot{\mathrm{V}} \mathrm{O}_{2 \text { peak }}$ (assessed by calculating the amount of time (minutes) throughout the exercise that was spent within $\pm 0.02 \mathrm{~g} \cdot \mathrm{min}^{-1}$ of the average fat oxidation rate, expressed as a percentage for each individual), which was greater when the 24 hour pre exercise period was controlled for dietary intake $(68.22 \pm 5.70 \%)$ compared to when only the evening meal preceding the testing session was controlled $(60.78 \pm 8.42 \%)$.

The standardised menu was based on typical foods consumed by participants at breakfast, lunch and dinner, and provided similar caloric intake to habitual dietary records (values as calorie totals and per kilogram mean bodyweight: energy intake: $2484.70 \mathrm{kcal} \cdot \mathrm{d}^{-1}$ (32.68 $\left.\mathrm{kcal} \cdot \mathrm{kg}^{-1} \cdot \mathrm{d}^{-1}\right)$; carbohydrate: $1127.7 \mathrm{kcal} \cdot \mathrm{d}^{-1}$ $\left(14.83 \mathrm{kcal} \cdot \mathrm{kg}^{-1} \cdot \mathrm{d}^{-1}\right)$; fat: $565.4 \mathrm{kcal} \cdot \mathrm{d}^{-1}\left(7.43 \mathrm{kcal} \cdot \mathrm{kg}^{-1} \cdot \mathrm{d}^{-1}\right)$ and protein: $791.96 \mathrm{kcal} \cdot \mathrm{d}^{-1}\left(10.42 \mathrm{kcal} \cdot \mathrm{kg}^{-1} \cdot \mathrm{d}^{-1}\right)$. Throughout the intervention period, participants were instructed to minimise consumption of polyphenol rich foods. Participants were additionally required to 
cycle for one hour at $50 \% \dot{\mathrm{V}} \mathrm{O}_{2 \text { peak }}$ three times per week as part of a regulated exercise programme. All participants provided training diaries to monitor compliance.

\section{Blood analyses}

All blood analyses for TFA were independently undertaken by ABS Laboratories (Biopark, Welwyn Garden City, Hertfordshire) employing previously validated methods [31]. TFA concentrations were based on assessment of palmitic, palmitoleic, stearic, oleic and linoleic acids. Briefly, $100 \mu \mathrm{l}$ plasma aliquots were spiked with internal standard (heptadecanoic acid), with free fatty acids being extracted using the 'Dole Extraction Solvent' (isopropanol/heptane/sulphuric acid (1 M) (40:10:1)). After drying under nitrogen, the extracts were resuspended using $200 \mu \mathrm{L}$ of dichoromethane and the FFAs derivatised using diethylamine and Deoxo-Fluor. The diethylamide derivatives were then extracted into heptane. The heptane was then removed using nitrogen in a dry-block at $70^{\circ} \mathrm{C}$. The dried extracts were reconstituted into $100 \mu \mathrm{L}$ of heptane and quantified by gas chromatography using a mass spectrometer as the detector in the selected ion monitoring (SIM) mode.

\section{Statistical analyses}

Statistical analyses were performed using SPSS (v19, Chicago, USA). Baseline variables were assessed using an independent samples $t$-test. A mixed design repeated measures analysis of variance (ANOVA) was employed to assess treatment and time interactions. Where pertinent, a one way ANOVA with Bonferroni post hoc adjustments was utilised to assess within treatment effects. An alpha level of $\leq 0.05$ was employed for statistical significance. Data are reported as means $\pm \mathrm{SE}$.

\section{Results}

\section{Baseline characteristics and resting measures}

Intervention groups were matched for age, height, weight, body fat and $\dot{\mathrm{V}} \mathrm{O}_{2 \text { peak }}$ at baseline (Table 1). A significant interaction effect for bodyweight was found across time only $(\mathrm{F}=16.98, P<0.001)$. Net bodyweight reduction was similar between groups across the intervention $(0.64 \pm 0.17 \mathrm{~kg}$ for $\mathrm{PL} ; \mathrm{F}=12.33, P=0.001$; $\eta \mathrm{p}^{2}=0.67$ ), and $0.60 \pm 0.21 \mathrm{~kg}$ for dGTE; $\mathrm{F}=6.27$, $P=0.014 ; \eta p^{2}=0.51$ within group). There was a significant group $\mathrm{x}$ time interaction for percentage body fat $(\mathrm{F}=7.81, P=0.002)$, with an overall reduction of $1.63 \pm 0.16 \%$ with dGTE $\left(P<0.001 ; \eta p^{2}=0.84\right.$ within group) compared to $0.66 \pm 0.15 \%$ for PL $\left(P=0.002 ; \eta \mathrm{p}^{2}=\right.$ 0.66 within group). No significant effects were reported for resting heart rate or blood pressure.

\section{Submaximal exercise measures}

Weekly contribution of substrate to total energy expenditure (EE) for PL and dGTE are reported in Figures 1 and 2 respectively. No significant differences were reported for EE either between or within groups over time $(P>0.05)$, demonstrating consistency of the submaximal exercise trials.

A significant overall group $\mathrm{x}$ time interaction for $\mathrm{FAT}_{\mathrm{TOT}}$ was observed $(\mathrm{F}=3.39, P=0.05)$. $\mathrm{FAT}_{\mathrm{TOT}}$ during exercise remained similar for PL across the intervention period (week $0=0.277 \pm 0.038 \mathrm{~g} \cdot \mathrm{min}^{-1}$; week $2=0.274 \pm$ $0.031 \mathrm{~g} \cdot \mathrm{min}^{-1}$; week $\left.4=0.279 \pm 0.030 \mathrm{~g} \cdot \mathrm{min}^{-1}, P>0.05\right)$ despite a non-significant increase in percentage contribution to total $\mathrm{EE}$ (week $0=34.61 \pm 3.72 \%$; week $2=35.23 \pm$ $2.99 \%$; week $4=35.53 \pm 2.53 \%, P>0.05)$.

FAT $_{\text {TOT }}$ for dGTE increased from $0.241 \pm 0.025 \mathrm{~g} \cdot \mathrm{min}^{-1}$ at week 0 to $0.256 \pm 0.023 \mathrm{~g} \cdot \mathrm{min}^{-1}$ at week 2 , and to $0.301 \pm 0.009 \mathrm{~g} \cdot \mathrm{min}^{-1}$ by week $4(\mathrm{~F}=4.10, P=0.05$; $\left.\eta \mathrm{p}^{2}=0.45\right)$. This represented a $24.9 \%$ or $0.060 \pm$ $0.027 \mathrm{~g} \cdot \mathrm{min}^{-1}$ increase in $\mathrm{FAT}_{\mathrm{TOT}}$ with dGTE. Correspondingly, percentage contribution of total fat to exercise EE increased with dGTE from $32.61 \pm 3.53 \%$ at week 0 to $34.71 \pm 2.57 \%$ at week 2 , and to $41.45 \pm 1.31 \%$ at week 4 $\left(\mathrm{F}=4.28, P=0.045 ; \eta \mathrm{p}^{2}=0.46\right)$.

A significant time interaction was observed only for $\mathrm{CHO}_{\text {TOт }}(\mathrm{F}=4.28, P=0.028)$. $\mathrm{CHO}_{\text {Tот }}$ reduced with dGTE from $1.203 \pm 0.078 \mathrm{~g} \cdot \mathrm{min}^{-1}$ at week 0 , to $1.144 \pm 0.044 \mathrm{~g} \cdot \mathrm{min}^{-1}$ at week 2 , and finally to $1.025 \pm$ $0.048 \mathrm{~g} \cdot \mathrm{min}^{-1}$ by week 4 , representing a reduction of $14.8 \%$ or $0.178 \pm 0.069 \mathrm{~g} \cdot \mathrm{min}^{-1}\left(\mathrm{~F}=4.02, P=0.05 ; \eta \mathrm{p}^{2}=0.45\right)$.

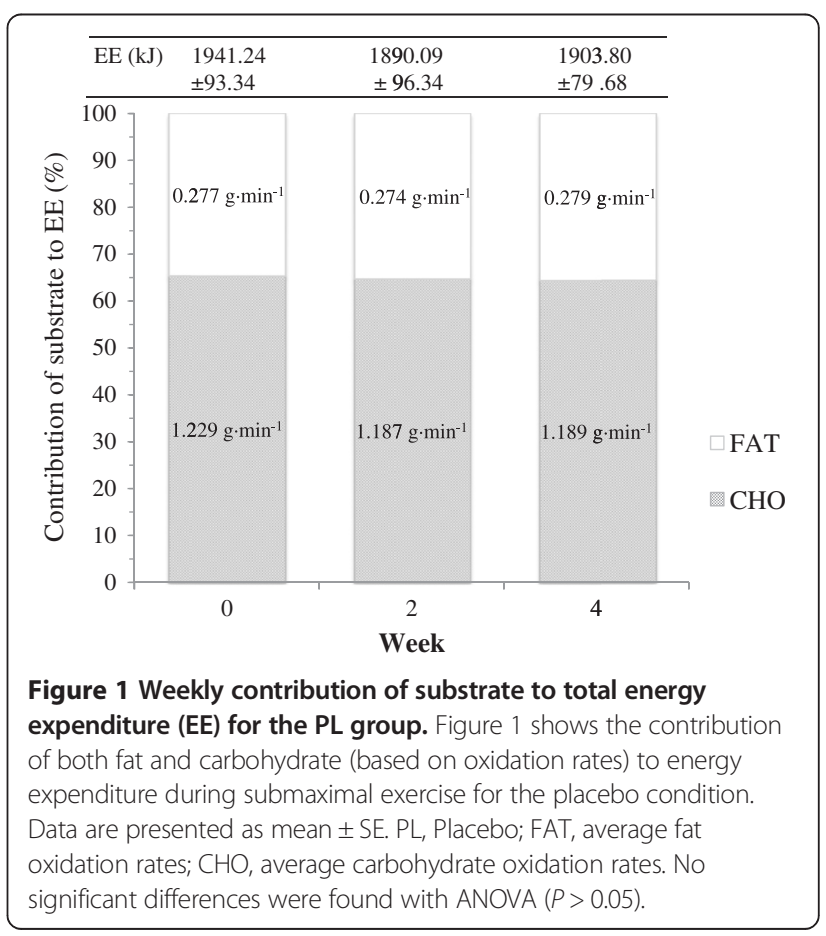




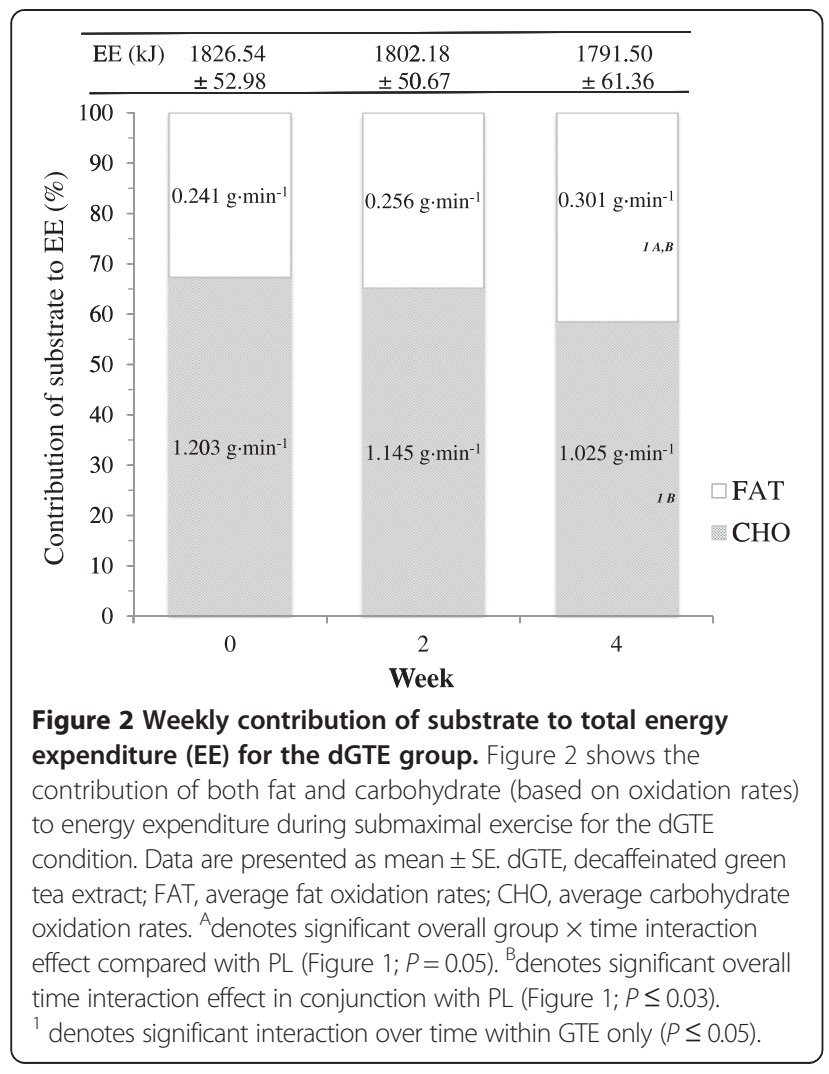

Correspondingly, percentage contribution of total $\mathrm{CHO}$ to exercise EE also reduced with dGTE from $67.39 \pm$ $3.53 \%$ at week 0 to $65.28 \pm 2.57 \%$ at week 2 , and to $58.55 \pm 1.31 \%$ at week $4\left(\mathrm{~F}=4.28, P=0.045 ; \eta \mathrm{p}^{2}=0.46\right)$. $\mathrm{CHO}_{\text {TOт }}$ and contribution of $\mathrm{CHO}$ to $\mathrm{EE}$ were largely unaffected with PL $(P>0.05)$.

Despite an improvement in $\mathrm{FAT}_{\mathrm{TOT}}$ for dGTE, no significant differences were observed for TFA concentrations either within or between groups pre-post intervention (Figure $3, P>0.05$ ). It was however noted that TFA concentrations were elevated pre-exercise by week 4 with PL $\left(249.3 \pm 46.2 \mu \mathrm{M} \cdot \mathrm{L}^{-1}\right.$ at week 0 to $315.4 \pm 98.1 \mu \mathrm{M} \cdot \mathrm{L}^{-1}$ at week 4 , a $26.5 \%$ increase, $P>0.05)$ and dGTE (227.9 \pm $37.6 \mu \mathrm{M} \cdot \mathrm{L}^{-1}$ at week 0 to $289.7 \pm 54.8 \mu \mathrm{M} \cdot \mathrm{L}^{-1}$ at week 4 , a $27.1 \%$ increase, $P>0.05$ ), with lack of significance most likely explained by individual variance.

It was also noted that whereas TFA concentrations reduced by $18.8 \%$ post exercise in the $\mathrm{PL}$ group from $616.5 \pm 114.8 \mu \mathrm{M} \cdot \mathrm{L}^{-1}$ at week 0 to $500.3 \pm 141.8 \mu \mathrm{M} \cdot \mathrm{L}^{-1}$ at week 4; post exercise TFA concentrations were maintained with dGTE $\left(509.3 \pm 90.0 \mu \mathrm{M} \cdot \mathrm{L}^{-1}\right.$ at week 0 to $514.3 \pm 71.1 \mu \mathrm{M} \cdot \mathrm{L}^{-1}$ at week 4 ), although no significant differences were reported within or between groups $(P>0.05)$. No significant differences were reported for any of the individual fatty acids measured.

Submaximal oxygen uptake values were not different across time either within or between groups (Table 2) demonstrating compliance to the set intensity $(P>0.05)$. No significant interaction effects were found for expired carbon dioxide, despite a modest reduction in $\dot{\mathrm{V}} \mathrm{CO}_{2}$ during submaximal exercise with dGTE from $1.31 \pm$ $0.05 \mathrm{~L} \cdot \mathrm{min}^{-1}$ at week 0 , to $1.25 \pm 0.05 \mathrm{~L} \cdot \mathrm{min}^{-1}$ at week $4 .(P>0.05)$. However, in conjunction with improved $\mathrm{FAT}_{\text {TOT }}$, a significant overall group $\times$ time interaction was observed for the respiratory exchange ratio (RER; $\mathrm{F}=3.30, P=0.05$ ), with values reducing from $0.90 \pm 0.01$ at week 0 to $0.87 \pm 0.01$ at week $4(\mathrm{~F}=4.36, P=0.044$; $\eta \mathrm{p}^{2}=0.47$, within group) supporting reduced reliance on $\mathrm{CHO}$ with dGTE. No such modifications for RER were observed with PL $(P>0.05)$.

Although submaximal exercise heart rate reduced by $6.24 \pm 3.85 \mathrm{~b} \cdot \mathrm{min}^{-1}(4.8 \%$ by week 4$)$ in the PL group, significance across time was only found with dGTE where submaximal exercise heart rate reduced by $8.8 \%$ from $124.95 \pm 3.69 \mathrm{~b} \cdot \mathrm{min}^{-1}$ at week 0 to $113.90 \pm 4.03$ $\mathrm{b} \cdot \mathrm{min}^{-1}$ at week $4\left(\mathrm{~F}=4.07, P=0.045 ; \eta \mathrm{p}^{2}=0.40\right)$. A significant overall group $\times$ time interaction was also found for $\mathrm{RPE}(\mathrm{F}=3.43, P=0.05)$, with subjects perceiving exercise to be progressively easier with dGTE by week 4 $(10.0 \pm 0.6$ relative effort rating) compared to week 0 $\left(11.9 \pm 0.4 ; P=0.015 ; \eta p^{2}=0.58\right)$. No differences were reported for systolic or diastolic blood pressure immediately post exercise over time for either group $(P>0.05)$.

\section{Performance measures}

A significant overall group $\times$ time interaction was found for distance covered ( $\mathrm{F}=9.84, P=0.001$; Figure 4). The use of dGTE resulted in a progressive increase in distance covered from $20.23 \pm 0.54 \mathrm{~km}$ at week 0 , to $21.77 \pm 0.49 \mathrm{~km}$ at week 2 and finally $22.43 \pm 0.40 \mathrm{~km}$ by week 4 , representing a $10.9 \%$ significant increase in performance $\left(\mathrm{F}=28.66, P<0.001 ; \eta \mathrm{p}^{2}=0.85\right)$. A similar interaction effect was also observed for $\mathrm{PL}(\mathrm{F}=7.94, P=0.009$; $\left.\eta \mathrm{p}^{2}=0.61\right)$ with distance covered significantly improving by week $2(21.75 \pm 0.40 \mathrm{~km})$ compared to week 0 $(20.79 \pm 0.30 \mathrm{~km} ; P=0.002)$ only.

In a similar manner, a significant overall group $\times$ time interaction was found for average power output $(\mathrm{F}=14.43$, $P<0.001$; Figure 4). Average power output increased with dGTE $\left(\mathrm{F}=40.01, P<0.001 ; \eta \mathrm{p}^{2}=0.89\right)$ by $17.9 \%$ or $29.02 \pm$ $5.53 \mathrm{~W}$ from week $0(162.06 \pm 10.08 \mathrm{~W})$ to week 2 $(191.08 \pm 10.85 \mathrm{~W} ; P=0.01$ ); and by $22.7 \%$ (or $36.85 \pm$ $3.20 \mathrm{~W})$ from week 0 to week $4(198.91 \pm 8.61 \mathrm{~W}$; $P<0.001)$, but was not significantly different between week 2 and $4(P>0.05)$. No significant differences across time for average power output were observed for PL $(P>0.05)$.

\section{Discussion}

The use of a 4 week dGTE strategy significantly enhanced FAT $_{\text {TOт }}$ by $24.9 \%$ or $0.060 \pm 0.027 \mathrm{~g} \cdot \mathrm{min}^{-1}$ compared to 


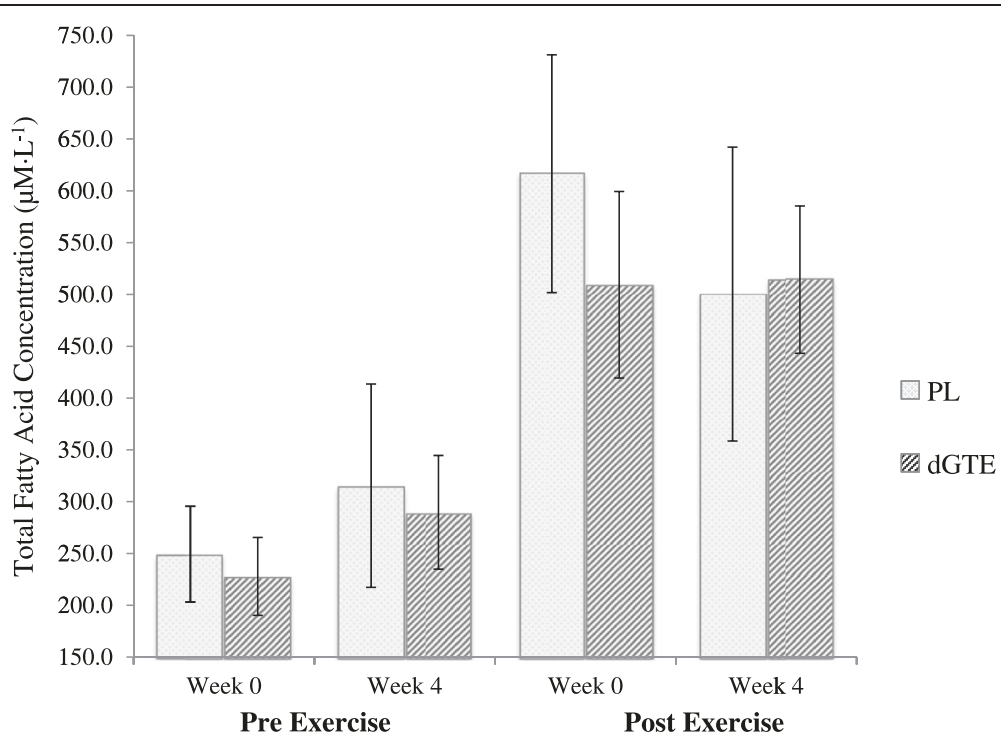

Figure 3 Total fatty acid concentrations pre and post exercise. Figure 3 shows the absolute total fatty acid concentrations at rest and post exercise for both treatment conditions at week 0 and week 4. Data are presented as mean \pm SE. PL, Placebo; $d G T E$, decaffeinated green tea extract. No significant differences were found with ANOVA $(P>0.05)$.

PL supporting the hypothesis set. The increased contribution of total fat to EE with dGTE supports the proposal that EGCG positively influences substrate utilisation, particularly in combination with exercise training. The use of a capsulated dGTE formula in the present study potentially offers a more practical means to regularly consume a sufficient daily dosage to elicit such effects (compared to consumption of 6-7 cups of green tea per day, especially considering the notable variability of catechin content in commercial green teas).

Improvements in $\mathrm{FAT}_{\mathrm{TOT}}$ have been demonstrated elsewhere $[1,11,32]$, with current values comparable to those reported when employing an acute dGTE strategy with similar EGCG content [3]. Conversely, higher dose
dGTE over a 28 day period did not enhance substrate metabolism in healthy, male volunteers [25] in contrast to these findings. However, in this latter study, the higher $\mathrm{FAT}_{\mathrm{TOT}}$ are more typical of endurance trained athletes. It has been inferred that the combined effect of exercise training and GTE may be more relevant for untrained individuals who 'respond' to GTE intervention [25]. Participants in this study were recreationally active. It is therefore plausible that adaptations in exercise metabolism with dGTE are more pronounced with less trained individuals, as opposed to physically active or endurance trained volunteers assessed elsewhere [23-25].

Improved $\mathrm{FAT}_{\mathrm{TOT}}$, and reduced reliance on $\mathrm{CHO}_{\mathrm{TOT}}$ during exercise are of clinical and performance relevance.

Table 2 Assessment of oxygen uptake, mean heart rate, perceived exertion and blood pressure related to submaximal exercise

\begin{tabular}{|c|c|c|c|c|c|c|}
\hline \multirow[b]{2}{*}{ Variable } & \multicolumn{3}{|l|}{$\mathrm{PL}(\mathrm{n}=7)$} & \multicolumn{3}{|c|}{ dGTE $(n=7)$} \\
\hline & Week 0 & Week 2 & Week 4 & Week 0 & Week 2 & Week 4 \\
\hline$\overline{\mathrm{V}} \mathrm{O}_{2}\left({\left.\mathrm{~L} \cdot \mathrm{min}^{-1}\right)}^{-1}\right.$ & $1.55 \pm 0.08$ & $1.51 \pm 0.08$ & $1.52 \pm 0.06$ & $1.46 \pm 0.04$ & $1.44 \pm 0.04$ & $1.44 \pm 0.05$ \\
\hline$\dot{\mathrm{V} C O} \mathrm{O}_{2}\left(\mathrm{~L} \cdot \mathrm{min}^{-1}\right)$ & $1.38 \pm 0.06$ & $1.35 \pm 0.06$ & $1.35 \pm 0.05$ & $1.31 \pm 0.05$ & $1.29 \pm 0.03$ & $1.25 \pm 0.05$ \\
\hline RER & $0.89 \pm 0.01$ & $0.89 \pm 0.01$ & $0.89 \pm 0.01$ & $0.90 \pm 0.01$ & $0.89 \pm 0.01$ & $0.87 \pm 0.01^{1 \mathrm{~A}, \mathrm{~B}}$ \\
\hline $\mathrm{HR}\left(\mathrm{b} \cdot \mathrm{min}^{-1}\right)$ & $127.8 \pm 5.5$ & $122.7 \pm 4.4$ & $121.5 \pm 3.8$ & $124.9 \pm 3.7$ & $117.0 \pm 2.5$ & $113.9 \pm 4.0^{1 \mathrm{~B}}$ \\
\hline RPE (6-20) & $11.1 \pm 0.8$ & $11.7 \pm 0.6$ & $11.6 \pm 0.3$ & $11.9 \pm 0.4$ & $11.2 \pm 0.4$ & $10.0 \pm 0.6^{* A}$ \\
\hline $\mathrm{SBP}(\mathrm{mm} \mathrm{Hg})$ & $132.7 \pm 2.9$ & $127.4 \pm 3.0$ & $127.7 \pm 2.9$ & $132.3 \pm 2.4$ & $127.6 \pm 1.8$ & $126.3 \pm 2.9$ \\
\hline $\mathrm{DBP}(\mathrm{mm} \mathrm{Hg})$ & $80.1 \pm 3.3$ & $74.7 \pm 1.9$ & $73.0 \pm 2.0$ & $74.4 \pm 1.8$ & $76.6 \pm 5.1$ & $70.1 \pm 3.5$ \\
\hline
\end{tabular}

Table 2 demonstrates the influence of the dGTE on cardio-respiratory measures during submaximal steady state exercise across the intervention. Data are presented as mean $\pm \mathrm{SE}$. PL, Placebo; dGTE, decaffeinated green tea extract; $\dot{\mathrm{VO}}_{2}$, submaximal oxygen uptake; $\dot{\mathrm{V}} \mathrm{CO}_{2}$, submaximal expired carbon dioxide; $\mathrm{RER}$, respiratory exchange ratio; $\mathrm{HR}$, heart rate; $\mathrm{RPE}$, rating of perceived exertion; SBP, systolic blood pressure; DBP, diastolic blood pressure. ${ }^{A}$ denotes significant overall group $x$ time interaction effect $(P \leq 0.05)$. ${ }^{B}$ denotes significant overall time interaction effect only $(P \leq 0.02)$. ${ }^{1}$ denotes significant within group time interaction effect only $(P \leq 0.045)$. ${ }^{*}$ denotes significant difference within group to baseline $(P=0.015)$. 


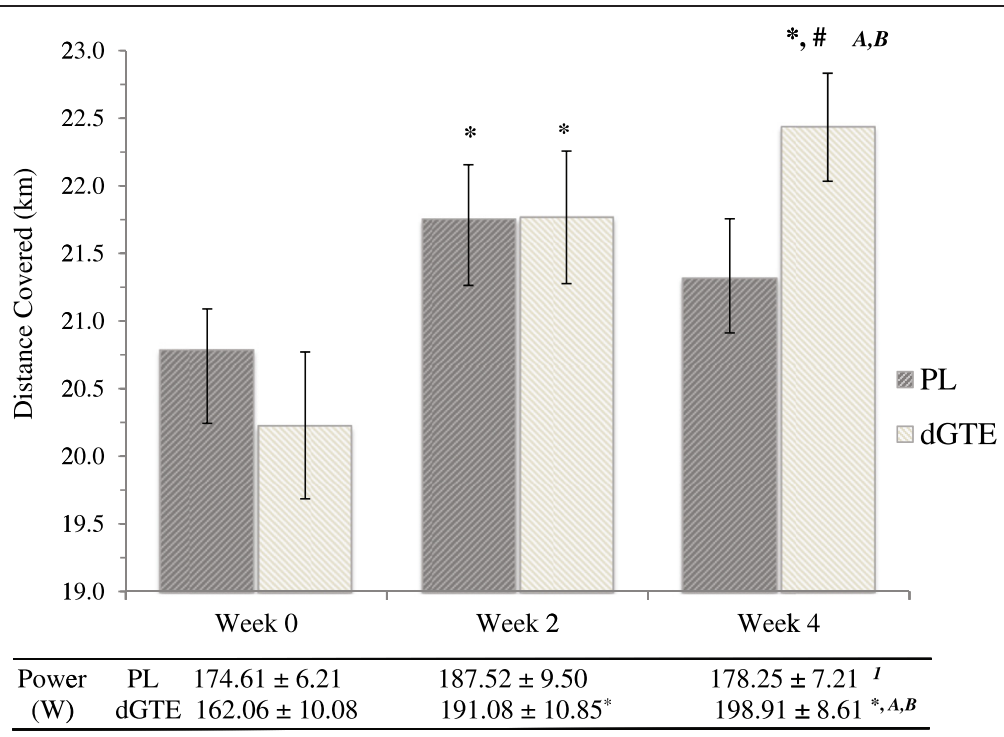

Figure 4 Distance covered and average power output during the performance trial. Figure 4 shows the distance covered and average power output elicited during the 40 minute performance trial for both treatment conditions at week 0,2 and 4 of the intervention. Data are presented as mean \pm SE. PL, Placebo; dGTE, decaffeinated green tea extract. ${ }^{A}$ denotes significant overall group $\times$ time interaction effect $(P \leq 0.001)$. ${ }^{B}$ denotes significant overall time interaction effect $(P<0.001)$. ${ }^{1}$ denotes significant within group time interaction effect only $(P=0.039) .{ }^{*}$ denotes significant difference $(P \leq 0.02)$ to baseline only within group. "denotes significant difference to week 2 within group only $(P=0.03)$.

Although resting and post exercise TFAs were not significantly different between groups, the increase in $\mathrm{FAT}_{\mathrm{TOT}}$ with dGTE supports the contention that the inhibition of COMT may not be a dominant mechanism.

Independently of antioxidant protective mechanisms, it has been proposed that EGCG positively modulates cell signalling via PGC1 $\alpha$ [20], sirtuin 1 (SIRT1) and mitogen activated protein kinase (MAPK) pathways $[33,34]$. In the longer term ( $>4$ weeks), it is feasible that EGCG at moderate dose facilitates up-regulation of gene expression leading to enhanced $\mathrm{FAT}_{\mathrm{TO}}$ with exercise.

Although bodyweight reductions were similar between groups, the use of dGTE combined with regulated exercise significantly reduced body fat compared to PL. These findings are similar to those reported elsewhere [10,32,35], particularly when either higher dose GTE or low dose caffeine has been employed. Alterations in body composition, coupled with increased $\mathrm{FAT}_{\text {TOT }}$ infer that catechin polyphenols favourably modulate cellular metabolism, possibly via a calorie restriction mimetic (CRM) action [36]. This contention is further supported via studies demonstrating enhanced glucose tolerance, insulin sensitivity and adiponectin levels with EGCG [3,37].

In the current study, resting and submaximal exercise heart rate and blood pressure decreased over the intervention period in both groups. However, results were only significant over time with dGTE for exercising heart rate and perceived exertion, possibly relating to substrate utilisation efficiency and improved exercise economy. Additionally, whilst the results could also indicate an acute training stimulus, non-significant reductions in SBP found were comparable to those observed elsewhere $[10,13,37]$. It is therefore suggested that any mild hypotensive effects are likely due to the short-term influence of regular aerobic activity on nitric oxide pathways than dGTE impacting on endothelial production of nitric oxide synthase.

There has been much interest in the use of GTE to enhance physical performance. In animal studies, time to exhaustion has been shown to improve with GTE by 8-24\%, with corresponding evidence of increased B-oxidation and fatty acid translocase/CD36 mRNA expression [38]. When relatively low GTE/EGCG doses have been employed in humans, improvements in time trial or performance measures have not been observed [22,24]. However, the inclusion of matched caffeine placebo or pre-exercise feeding may explain these findings. Conversely, with higher dose GTE strategies, improvements in maximal oxygen uptake and time trial performance have been observed $[39,40]$.

To the authors' knowledge, this is the first study to demonstrate a significant impact of dGTE on subsequent exercise performance. Performance indices improved by $10.9 \%$ for distance covered, and $22.7 \%$ for average power output with dGTE. This is unlikely to be fully explained via a training effect as improvements with PL were only observed at week 2 of the trial. Reduced reliance on $\mathrm{CHO}_{\mathrm{TOT}}$ may have contributed to improved performance following submaximal exercise. 
Future research investigating specific effects of EGCC from dGTE on exercise tolerance, performance and recovery is warranted, particularly in light of metabolomic advances [41]. High dose GTE has been demonstrated to reduce muscle soreness following strenuous exercise [42], potentially via signalling interactions leading to reduced post exercise inflammatory cascades [43]. Results in the current study may have been augmented due to utilisation of a low polyphenol diet. Further research combining dietary polyphenols with dGTE is warranted.

\section{Conclusions}

In conclusion, dGTE in conjunction with exercise training reduced relative $\mathrm{FAT}_{\mathrm{TOT}}$ and body composition in recreationally active, male volunteers. Improved metabolic efficiency during submaximal exercise may potentiate improved metabolic economy and hence adherence to longer term training programmes. Combined with the observed impact of dGTE on subsequent performance indices, this supports the contention that EGCG use may modulate cellular signalling pathways leading to more efficient substrate use, resulting in improved exercise output.

\section{Abbreviations \\ $\mathrm{CHO}$ : Carbohydrate; $\mathrm{CHO}_{\text {тот: }}$ Total carbohydrate oxidation rate (measured in $\left.\mathrm{g} \cdot \mathrm{min}^{-1}\right)$; COMT: Catechol-o-methyl transferase; dGTE: Decaffeinated green tea extract; $\mathrm{EE}$ : Energy expenditure (measured in $\mathrm{kJ} \cdot \mathrm{min}^{-1}$ ); EGCG: (-)-Epigallocatechin-3-gallate; FAT TOT: Total fat oxidation rate (measured in $\mathrm{g} \cdot \mathrm{min}^{-1}$ ); GT: Green tea; PL: Placebo formula used in the study; RER: Respiratory exchange ratio the ratio from dividing expired carbon dioxide with oxygen uptake; RPE: Rating of perceived exertion; TFA: Total fatty acids; $\dot{\mathrm{V}} \mathrm{O}_{2}$ : Volume of oxygen uptake (measured in L.min ${ }^{-1}$ ); $\dot{\mathrm{V}} \mathrm{O}_{2 \text { peak }}$ : Peak oxygen uptake (measured in $\mathrm{L} \cdot \mathrm{min}^{-1}$ ); $\dot{\mathrm{V}} \mathrm{CO}_{2}$ : Volume of expired carbon dioxide (measured in $\mathrm{L} \cdot \mathrm{min}^{-1}$ ).}

\section{Competing interests}

Research funding and product supply to support this study was received from High $5 \mathrm{Ltd}$. All data was collected, analysed and reported by the investigatory team fully independently of the company. The authors declare that they have no competing interest.

\section{Authors' contributions}

All authors were involved in the study. JDR was the principal researcher, involved with liaison with the company, project organisation, statistical analysis and manuscript generation; MGR was co-supervisor involved with project co-ordination, quality control and technical accuracy in preparation of the manuscript; MDT was involved with confirmation of statistical analyses, and manuscript editing; JCW and CHT were involved with participant recruitment, pilot data collection, experimental interventions, data analysis and manuscript editing. All authors read and approved the final manuscript.

\author{
Acknowledgements \\ The authors wish to acknowledge High5 Ltd. for providing the support \\ and funding to undertake this study. dGTE was supplied by High $5 \mathrm{Ltd}$. \\ independently of the investigatory team. The authors also wish to \\ acknowledge the support and external collaboration with ABS \\ Laboratories, Biopark, Welwyn Garden City, for independent \\ assessment of blood samples.
}

Received: 6 November 2014 Accepted: 16 December 2014

Published online: 21 January 2015

\section{References}

1. Dulloo AG, Duret C, Rohrer D, Girardier L, Mensi N, Fathi M, et al. Efficacy of a green tea extract rich in catechin polyphenols and caffeine in increasing 24-h energy expenditure and fat oxidation in humans. Am J Clin Nutr. 1999;70:1040-50.

2. Ryu OH, Lee J, Lee KW, Kim HY, Seo JA, Kim SG, et al. Effects of green tea consumption on inflammation, insulin resistance and pulse wave velocity in type 2 diabetes patients. Diabetes Res Clin Pract. 2006;71:356-8.

3. Venables MC, Hulston CJ, Cox HR, Jeukendrup AE. Green tea extract ingestion, fat oxidation, and glucose tolerance in healthy humans. Am J Clin Nutr. 2008:87:778-84.

4. Mukhtar H, Ahmad N. Tea polyphenols: prevention of cancer and optimizing health. Am J Clin Nutr. 2000;71(6):1698S-702.

5. Maki KC, Reeves MS, Farmer M, Yasunaga K, Matsuo N, Katsuragi Y, et al. Green tea catechin consumption enhances exercise-induced abdominal fat loss in overweight and obese adults. J Nutr. 2009;139(2):264-70.

6. Moore RJ, Jackson KG, Minihane AM. Green tea (Camellia Sinensis) catechins and vascular function. Br J Nutr. 2009;102(12):1790-802.

7. Nantz MP, Rowe CA, Bukowski JF, Percival SS. Standardised capsule of Camellia sinensis lowers cardiovascular risk factors in a randomized, double-blind, placebo-controlled study. Nutr. 2009;25(2):147-54.

8. Valcic S, Burr JA, Timmermann BN, Liebler TC. Antioxidant chemistry of green tea catechins. New oxidation products of (-)-epigallocatechin gallate and (-)-epigallocatechin from their reactions with peroxyl radicals. Chem Res Toxicol. 2000;13(9):801-10.

9. Henning SM, Niu Y, Lee NH, Thames GD, Minutti RR, Wang H, et al. Bioavailability and antioxidant activity of tea flavanols after consumption of green tea, black tea, or a green tea extract supplement. Am J Clin Nutr. 2004:80:1558-64.

10. Nagao T, Hase T, Tokimitsu I. A green tea extract high in catechins reduces body fat and cardiovascular risks in humans. Obesity. 2007;15(6):1473-83.

11. Ichinose T, Nomura S, Someya Y, Akimoto S, Tachiyashiki K, Imaizumi K. Endurance training supplemented with green tea extract on substrate metabolism during exercise in humans. Scand J Med Sci Sports. 2011;21:598-605.

12. Galleano M, Pechanova O, Fraga CG. Hypertension, nitric oxide, and dietary plant polyphenols. Curr Pharm Biotech. 2010;11(8):837-48.

13. Brown AL, Lane J, Coverly J, Stocks J, Jackson S, Stephen A, et al. Effects of dietary supplementation with the green tea polyphenol epigallocatechin-3gallate on insulin resistance and associated metabolic risk factors: a randomised control trial. Br J Nutr. 2009;101(6):886-94.

14. Rains TM, Agarwal S, Maki KC. Antiobesity effects of green tea catechins: a mechanistic review. J Nutr Biochem. 2011;22(1):1-7.

15. Phung OJ, Baker WL, Matthews $\sqcup$, Lanosa M, Thorne A, Coleman Cl. Effect of green tea catechins with or without caffeine on anthropometric measures: a systematic review and meta-analysis. Am J Clin Nutr. 2010;91(1):73-81.

16. Hursel R, Viechtbauer W, Westerterp-Plantenga MS. The effects of green tea on weight loss and weight maintenance: A meta-analysis. Int J Obes. 2009;33(9):956-61.

17. Hursel R, Westerterp-Plantenga MS. Thermogenic ingredients and body weight regulation. Int J Obes. 2010;34(4):659-69.

18. Feng WY. Metabolism of green tea catechins: An overview. Curr Drug Metab. 2006;7(7):755-809.

19. Chen C, Wang CY, Lambert JD, Ali N, Welsh WJ, Yang CS. Inhibition of human liver catechol-O-methyltransferase by tea catechins and their metabolites: structure-activity relationship and molecular-modelling studies. Biochem Pharma. 2005;69(10):1523-31.

20. Hodgson $A B$, Randell RK, Jeukendrup AE. The effect of green tea extract on fat oxidation at rest and during exercise: Evidence of efficacy and proposed mechanisms. Adv Nutr. 2013;4:129-40.

21. Reiter CEN, Kim JA, Kwon MJ. Green tea polyphenol epigallocatechin gallate reduces endothelin-1 expression and secretion in vascular endothelial cells: Roles for AMP activated protein kinase, Akt and FOXO1. Endocrinol. 2009;151(1):103-14.

22. Dean $\mathrm{S}$, Braakhuis A, Paton C. The effects of EGCG on fat oxidation and endurance performance in male cyclists. Int I Sport Nutr Exerc Metab. 2009;20(6):624-44.

23. Eichenberger $P$, Colombani PC, Mettler S. Effects of a 3-week consumption of green tea extracts on whole-body metabolism during cycling exercise in endurance-trained men. Int J Vitam Nutr Res. 2009;79(1):24-33. 
24. Eichenberger $\mathrm{P}$, Mettler S, Arnold M, Colombani PC. No effects of three-week consumption of a green tea extract on time trial performance in endurance trained men. Int J Vitam Nutr Res. 2010;80(1):54-64.

25. Randell RK, Hodgson AB, Lotito SB, Jacobs DM, Rowson M, Mela DJ. Variable duration of decaffeinated green tea extract ingestion on exercise metabolism. Med Sci Sports Exerc. 2014;46(6):1185-93.

26. Faul F, Erdfelder E, Lang A-G, Buchner A. G*power 3: a flexible statistical power analysis program for the social, behavioral, and biomedical sciences. Behav Res Meth. 2007;39(2):175-91.

27. Roberts JD, Tarpey MD, Kass LS, Tarpey RJ, Roberts MG. Assessing a commercially available sports drink on exogenous carbohydrate oxidation, fluid delivery and sustained exercise performance. J Int Soc Sports Nutr. 2014;11(8):1-14.

28. Kao M-F, Lu H-K, Jang T-R, Yang W-C, Chen C-H, Chen Y-Y, et al. Comparison of different measurement equations for body composition estimation in male athletes. Int J Sport Exerc Sci. 2010;3(1):11-6.

29. Borg G. Ratings of perceived exertion and heart rates during short term cycle exercise and their use in a new strength test. Int J Sports Med. 1982;3(3):153-8.

30. Jeukendrup AE, Wallis GA. Measurement of substrate oxidation during exercise by means of gas exchange measurements. Int J Sports Med. 2005;26(1):S28-37.

31. Kangani CO, Kelley DE, DeLany JP. New method for GC/FID and GC-C-IRMS analysis of plasma free fatty acid concentration and isotopic enrichment. J Chromatogr B Analyt Technol Biomed Life Sci. 2008;873(1):95-101.

32. Westerterp-Plantenga MS, Lejeune MPGM, Kovacs EMR. Body weight loss and weight maintenance in relation to habitual caffeine intake and green tea supplementation. Obes Res. 2005;13:1195-204.

33. Ayissi VBO, Ebrahimi A, Schluesenner H. Epigenetic effects of natural polyphenols: a focus on SIRT1-mediated mechanisms. Mol Nutr Food Res. 2014;58:22-32

34. Kim H-S, Quon MJ, Kim J-A. New insights into the mechanisms of polyphenols beyond antioxidant properties: lessons from the green tea polyphenol, epigallocatechin 3-gallate. Redox Biol. 2014;2:187-95.

35. Wang H, Wen Y, Du Y, Yan X, Guo H, Rycroft JA, et al. Effects of catechin enriched green tea on body composition. Obesity. 2010;18:773-9.

36. Madeo F, Pietrocola F, Eisenberg T, Kroemer G. Calorie restriction mimetics: towards a molecular definition. Nat Rev: Drug Disc. 2014;13(10):727-40.

37. Potenza MA, Marasciulo FL, Tarquinio M, Tiravanti E, Colantuono G, Federic A, et al. EGCG, a green tea polyphenol, improves endothelial function and insulin sensitivity, reduces blood pressure, and protects against myocardial I/R injury in SHR. Am J Physiol Endocrinol Metab. 2007;292:E1378-87.

38. Murase T, Haramizu S, Shimotoyodome A, Tokimitsu I, Hase T. Green tea improves running endurance in mice by stimulating lipid utilization during exercise. Am J Physiol Reg Integr Comp Physiol. 2006;290(6):R1550-6.

39. MacRae HSH, Mefferd KM. Dietary antioxidant supplementation combined with quercetin improves cycling time trial performance. Int J Sport Nutr Exer Metab. 2006;16(4):405-19.

40. Richards JC, Lonac MC, Johnson TK, Schweder MM, Bell C. Epigallocatechin3-gallate increases maximal oxygen consumption in adult humans. Med Sci Sports Exerc. 2010;42(4):739-44.

41. Nieman DC, Gillitt ND, Knab AM, Shanely RA, Pappan KL, Jin F, et al. Influence of a polyphenol-enriched protein powder on exercise-induced inflammation and oxidative stress in athletes: a randomized trial using a metabolomics approach. Plos One. 2013;8(8):1-11.

42. Moradpourian MR, Ashkavand Z, Venkatesh C, Vishwanath BS. Effect of different doses of green tea on oxidative stress and muscle soreness in downhill treadmill running. Asian J Pharm Clin Res. 2014;7(2):192-3.

43. Cunha CA, Lira FS, Neto JCR, Pimentel GD, Souza GIH, da Silva CMG, et al. Green tea extract supplementation induces the lipolytic pathway, attenuates obesity, and reduces low-grade inflammation in mice fed a high-fat diet. Mediators Inflamm. 2013;2013:1-8.

\section{Submit your next manuscript to BioMed Central and take full advantage of:}

- Convenient online submission

- Thorough peer review

- No space constraints or color figure charges

- Immediate publication on acceptance

- Inclusion in PubMed, CAS, Scopus and Google Scholar

- Research which is freely available for redistribution

Submit your manuscript at www.biomedcentral.com/submit 